\title{
Internet Reference Sources for Computing and Computer Science:
}

\author{
A Selected Guide \\ Michael Knee \\ Science Bibliographer and Reference Librarian \\ University at Albany, SUNY \\ Science Library \\ Albany, NY 12222 \\ knee@albany.edu
}

SUMMARY. Computing and computer science bibliographic databases, bibliographies, dictionaries, encyclopedias, directories, and guides, along with finding aids for technical reports, online books, and book reviews are listed and described. Subscription-based sources as well as free alternatives are covered. Resources are listed for all levels of computing ability including faculty and professionals, graduate students, undergraduates, and general users.

\section{INTRODUCTION}

Computer scientists and computing professionals were early users of the Internet and related technologies. From electronic mail to gopher sites to the World Wide Web, 
as a group, they harnessed the capabilities of the Internet for communications, information dissemination, cooperative work, and research. Previously, computer science Internet resources were examined and described. ${ }^{1,2}$ This article concentrates on reference Internet sources for computing and computer science. It includes a combination of resources cited in the two previous articles, along with new material. The older information has updated URLs and descriptions.

\section{BIBLIOGRAPHIC DATABASES}

Bibliographic databases evolved from indexing and abstracting services. In many cases, they are the electronic equivalent of a paper-based indexing and abstracting services with enhanced search capabilities. The purpose of databases is to assist researchers and students in locating relevant sources of information. Each databases is different, but generally, source material covered includes journal and magazine articles, conference papers, master's theses, doctoral dissertations, technical reports, government documents and reports, books, and book chapters.

Inspec is the most comprehensive bibliographic database for computer science. It is the electronic counterpart of three indexing and abstracting services: Computer \& Control Abstracts, Electrical \& Electronics Abstracts, and Physics Abstracts. The main database covers from 1969 forward, with an optional archive covering 1898-1968. Inspec is available on CD-ROM, magnetic tape, or online. Online it is hosted by several vendors including Dialog, EBSCO, Ovid, Proquest, and STN, and available by subscription or pay per search. Inspec should be available in most libraries supporting computer science research programs. 
The Guide to Computing Literature < http://portal.acm.org/guide.cfm> (11 November 2004) from the Association for Computing Machinery (ACM) is another valuable bibliographic resource. Starting out as the Comprehensive Bibliography of Computing Literature in 1960 and becoming the ACM Guide to Computing Literature in 1977, it has a long history that evolved from print to CD-ROM to online. Coverage in The Guide to Computing Literature dates back as far as 1947 for some publication, and is especially strong for ACM journals, transactions, magazines, and conference proceedings. Basic search and browse functions are freely available. Subscribers and ACM members have access to advanced search features.

Another extensive database, that is fairly new, is Computer Science Index. It corresponds to the ceased print index Computer Literature Index. However, its publisher EBSCO enhanced the coverage with additional professional and popular computing publications along with citations from numerous scholarly journals including titles from the ACM, IEEE, and other major publishers. Coverage extends back to the mid-1950s for some of the content, and full text is available for some of the citations.

Other noteworthy research level computer science databases are Computer and Information Systems Abstracts from Cambridge Scientific Abstracts, CompuScience

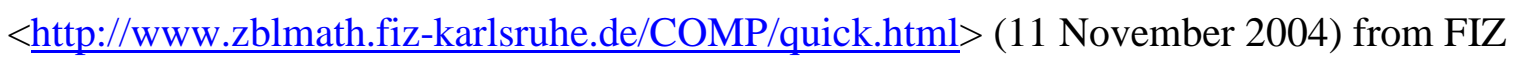
Karlsruhe, Computer Source, a full text database produced by EBSCO, Computer Abstracts International Database published by Emerald, and Computer \& Communications Security Abstracts from Emerald.

Institutions not requiring a research level database may consider subscribing to EBSCO’s Internet \& Personal Computing Abstracts or Wilson's Applied Science and 
Technology Index. Another option is an aggregator database such as EBSCO's Academic Search Premier that contains about 450 computing and computer science titles or InfoTrak OneFile from Thomson Gale, which covers nearly 350 titles in computing and computer science. Both EBSCO and Thomson Gale offer aggregators with fewer overall and computing and computer science titles.

There are additional options. For a long time, computer scientists have compiled and depended on bibliographies to help organize and control the information for a specialized subject, and advance their research. Bibliographies have appeared in paper format as books, journal articles, as serials, and at the end of articles. Since its rise in popularity, many bibliographies have appeared on the World Wide Web. These bibliographies often have powerful search capabilities. Several are listed below; all are freely accessible.

Annotated Computer Vision Bibliography.

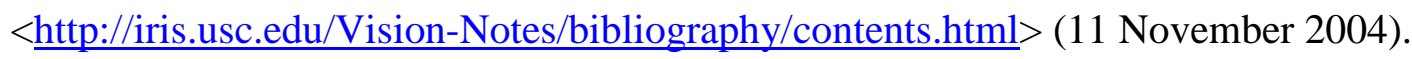

BibFinder: A Computer Science Bibliography Mediator.

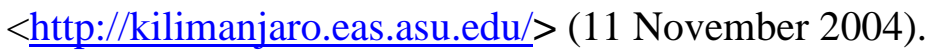

BibFinder is a computer science bibliography search engine. It simultaneously searches The Collection of Computer Science Bibliographies, the DBLP Computer Science Bibliography, the ACM Digital Library, The Guide to Computing Literature, the Network Bibliography, Elsevier’s ScienceDirect, IEEE Xplore, CiteSeer, and Google. 


\section{Bibliography of Automated Deduction.}

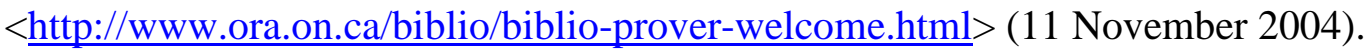

The Collection of Computer Science Bibliographies.

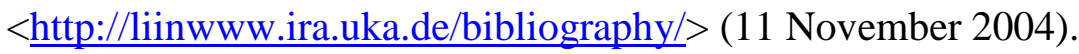

Covering most areas of computer science, this collection of bibliographies contains more than 1,400,000 records from nearly 1,400 bibliographies. It may be searched in its entirety or individual bibliographies may be selected and searched. Technical reports from computer science departments may be searched separately.

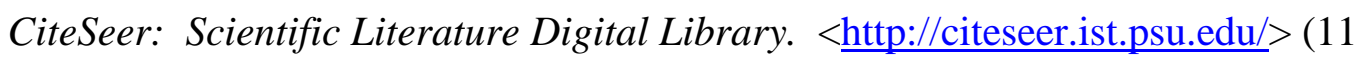
November 2004).

CiteSeer is a search system providing access to journal articles, conference papers, and technical reports in computer science and allied sciences. In addition to a list of documents, an author or subject search automatically generates the search context and a list of related documents. The autonomous citation indexing feature executes a citation search similar to Science Citation Index.

Computer Graphics Bibliography Database.

<http://www.siggraph.org/publications/bibliography/> (11 November 2004).

Cryptology ePrint Archive. <http://eprint.iacr.org/> (11 November 2004). 
DBLP Computer Science Bibliography. <http://dblp.uni-trier.de/> (11 November 2004). $D B L P$ started as a bibliography for database systems and logic programming, but expanded its scope to include other areas of computer science. DBLP is currently an acronym for Digital Bibliography and Library Project, and contains over 500,000 references.

ECS EPrints Service. <http://eprints.ecs.soton.ac.uk/> (11 November 2004).

The ECS EPrints Service is a publications database for electronics and computer science.

Electronic Colloquium on Computational Complexity (ECCC).

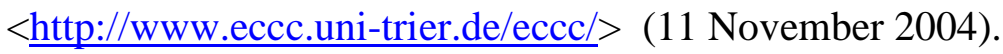

The Garbage Collection Bibliography.

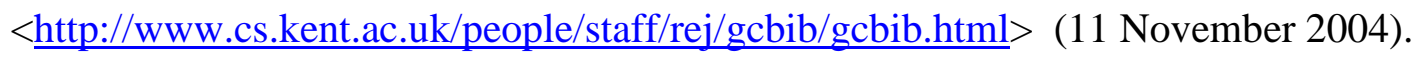

For the purpose of this resource, garbage collection is defined as automatic dynamic memory management.

HCI Bibliography. <http://www.hcibib.org/> (11 November 2004).

The HCI Bibliography is a searchable bibliography on human-computer interaction.

Network Bibliography. <http://www.cs.columbia.edu/ hgs/netbib/> (11 November 2004). 
Containing about 50,000 entries, this bibliography covers the subjects of computer networks, performance evaluation, computer-supported cooperative work, network security, digital signal processing, and related topics.

ÖFAI - IMKAI Library Information System BIBLIO.

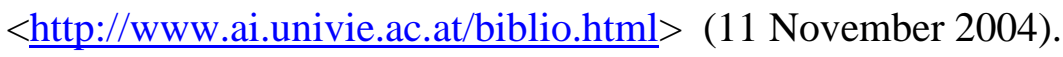

This bibliography lists books, journal articles, conference papers, and research papers on artificial intelligence.

RAND Corporation: Books and Publications: Bibliographies and Abstracts.

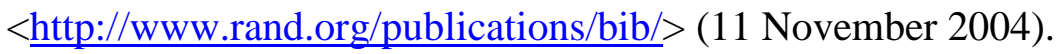

The RAND Corporation is a nonprofit organization that focuses its efforts on research and analysis of challenges that face the U.S. and the world. RAND produces a variety of publications to communicate and disseminate its research results including briefings, reports, articles, and monographs. This Web page lists subject-oriented bibliographies of RAND publications. A few of the bibliographies have a computing theme. Many of the publications are freely available on the RAND Web site.

Software History Bibliography. <http://www.cbi.umn.edu/shp/bibliography.html > (11 November 2004).

Compiled by the Charles Babbage Institute, this bibliography lists about 2,500 citations to books, journal articles, magazine articles, conference papers, reports, oral histories, and archival materials on the history of software. 


\section{TECHNICAL REPORTS}

Academic institutions as well as government, industrial, and corporate research installations issue technical reports. Technical reports are important sources of information in computer science. Sometimes they are revised and published as journal articles or conference papers. However, many are never published, and may be difficult to locate. The resources listed below are useful finding aids for technical reports.

GrayLIT Network: A Science Portal of Technical Reports. <http://graylit.osti.gov/> (11 November 2004).

GrayLit Network is a portal for technical report information generated through federally funded research and development projects. It is a free database that provides access to full text scientific and technical reports from the following U.S. government agencies: Defense Technical Information Center, Department of Energy, NASA, and Environmental Protection Agency. Reports are available back to 1960, but most are from the early 1990s forward.

Networked Computer Science Technical Reports Library (NCSTRL).

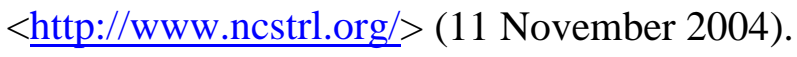

NCSTRL is a collection of research reports and papers from institutions around the world awarding doctoral degrees in computer science or engineering, and some industrial and government research laboratories. It may be searched by author, title, or abstract 
keywords, and limited by institution and date. It may also be browsed by institution. Full text is usually available.

NTIS. <http://www.ntis.gov/> (11 November 2004).

The National Technical Information Service maintains and disseminates a large collection of scientific, technical, engineering, and business-related information produced for and by U.S. government agencies. The freely accessible NTIS database contains the records of millions of publications from 1990 forward, along with audiovisual materials, computer data files, and software. All records include an abstract; some of the publications are freely available on the Internet. Other documents and materials may be purchased from NTIS or found in depository libraries.

\section{On-line CS Techreports.}

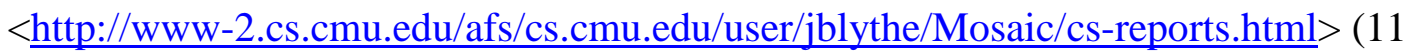
November 2004).

On-line CS Techreports lists and links to over 650 institutions around the world that make their computer science technical reports available online. The institutions are arranged in loose alphabetical order, and can be sorted by country.

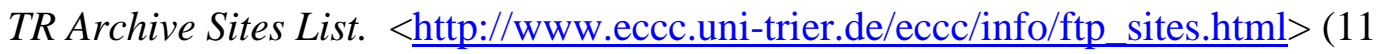
November 2004). 
This Web site lists academic and research institutions around the world that distribute online computer science technical reports. The institutions are arranged in alphabetical order.

The Virtual Technical Reports Center. <http://www.lib.umd.edu/ENGIN/TechReports/Virtual-TechReports.html > (11 November 2004).

The Virtual Technical Reports Center lists and links to institutions or corporations around the world that provide either full text or abstracts of technical reports, preprints, reprints, dissertations, theses, and research reports. The institutions are arranged in alphabetical order.

\section{BOOKS}

Even in computing and computer science, online books have not been fully embraced. Perhaps, they have not evolved far enough, or is it us, who have not evolved? Maybe when the generation that was born in the digital age becomes the predominant users, online books will be more accepted. There are several vendors and publishers that offer online computing and computer science books by subscription or pay per title.

Safari Books Online < http://www.safaribooksonline.com/> (11 November 2004) provides access to numerous up-to-date titles from leading computing and information technology publishers. Their collection contains books from Adobe Press, Addison Wesley Professional, Cisco Press, New Riders, O'Reilly, Peachpit Press, Prentice Hall PTR, Que, and Sams Publishing. Online computer science books from CRC Press can be found via 
four portals: ENGnetBASE < http://www.engnetbase.com/> (11 November 2004),

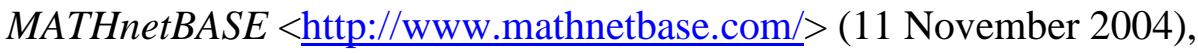
ITknowledgeBASE < $<$ http://www.itknowledgebase.net $>$ (11 November 2004), and InfoSECURITYnetBASE < $<$ http://infosecuritynetbase.com/> (11 November 2004). Reference and standard texts are available through these portals. Ebrary $<\underline{\text { http://www.ebrary.com/> }}$ (11 November 2004) contains a considerable collection of computing and computer science books from publishers like Kluwer, Idea Group Publishing, Charles River Media, Marcel Dekker, Cambridge University Press, Routledge, Peter Collin Publishing, Johns Hopkins University Press, McGraw-Hill, John Wiley \& Sons, and Coriolis Group. Although mostly standard texts are available, there are a few reference books. Containing mainly texts and a few reference books,

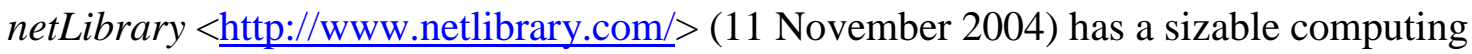
and computer science collection. It includes books from MIT Press, Gale, Sams Publishing, O’Reilly, Kluwer, McGraw-Hill, Oxford University Press, Idea Group Publishing, Que, John Wiley \& Sons, and Lawrence Erlbaum Associates. Xreferplus

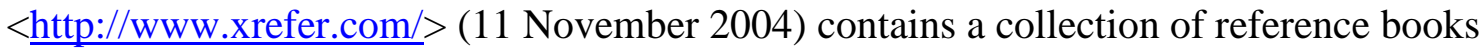
(dictionaries, encyclopedias, and thesauri) with a cross-reference linking structure. Its technology section has several computing and computer-related dictionaries. Kluwer

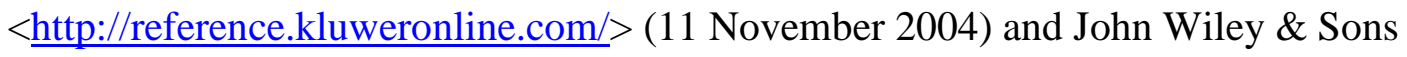

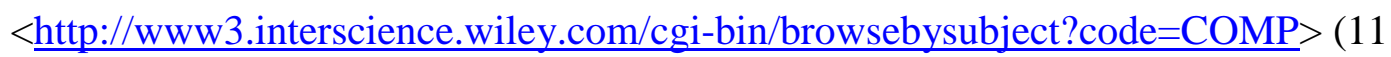
November 2004), Books24x7 <http://www.books24x7.com>(11 November 2004) also offer online computer science reference books. 
In addition to these fee-based services, there are several gateways to collections of free online books. Titles in the public domain as well as copyrighted books are available.

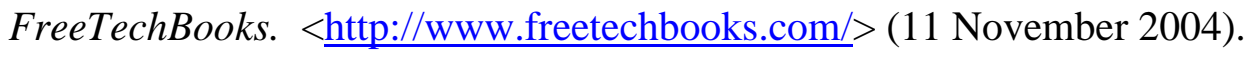
This site provides links to free online computer books and documentation. There are over 100 books covering programming languages, scripting languages, operating systems, and other computer science topics like data structures, algorithms, objectoriented programming, logic programming, compiler design, software development, and game development.

IBM Redbooks. <http://www.redbooks.ibm.com/> (11 November 2004).

Developed and published by IBM's International Technical Support Organization, Redbooks provide guidance, installation and implementation experiences, solution scenarios, and "how-to" guidelines. Sample code and other support materials are often included. They are accessible by keyword search, publication date, or subject domains.

National Academies Press: Computer Sciences.

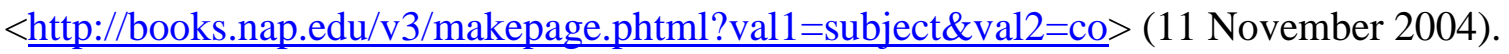
The National Academies Press offers free access to numerous books and reports on many subjects. Listing titles in reverse chronological order, this Web page covers the subjects of computing, information technology, and related technologies.

The Online Books Page: Call Numbers Starting With QA. 


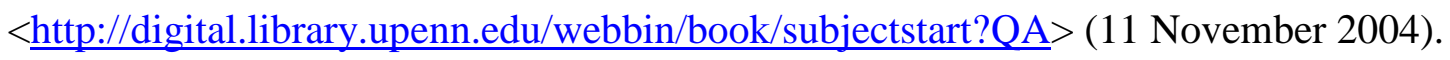

This Web page from the University of Pennsylvania Libraries lists over 400 books classified in the Library of Congress QAs and covering computer science and mathematics. The titles may be perused; or author and title search and browse functions

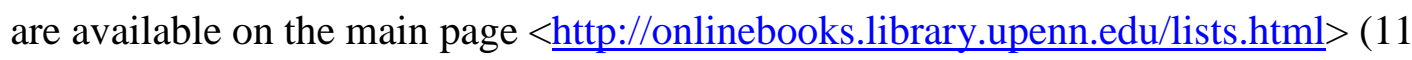
November 2004).

\section{BOOK REVIEWS}

For computing and computer science, there are two subscription-based book review services. Computing Reviews $<$ http://reviews.com/ $>$ (11 November 2004) is produced through a partnership between the Association of Computing Machinery and reviews.com. It selectively reviews general and specialized books as well as journal articles, conference proceedings, theses, technical reports, and Web resources. Computing Reviews is continually updated, and has many browse, search, and

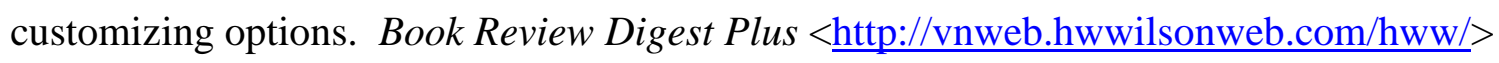
(11 November 2004) from H. W. Wilson is the other source. Covering most academic subjects, it is the online, expanded version of Book Review Digest. In addition to the reviews from Book Review Digest, it also includes reviews from eleven other Wilson indexes/databases including Applied Science \& Technology Index, General Science Index, and Business Periodical Index. Besides these resources, the following Web sites provide free access to quality reviews for computing and computer science books. 
ACCU: Book Reviews. <http://www.accu.org/bookreviews/public/> (11 November 2004).

The Association of C \& C++ Users (ACCU) furnishes access to book reviews that appeared in their journals $C V u$ and Overload. The reviews are brief, but cover many computing subjects. They can be browsed by subject, publisher, journal issue, reviewer, title, author, and those highly recommended. A search engine is also available.

Electronic Review of Computer Books (ERCB). <http://www.ercb.com/> (11 November 2004).

From the publishers of Dr. Dobb's Journal, ERCB contains independent reviews of books about computer hardware, software, and networks. It includes both brief and feature reviews. The "Programmer’s Bookshelf" column back to 1990 is also available. A search engine and a catalog provide access to the reviews.

KickstartNews: Computer Book Reviews. < (11 November 2004).

This Web site offers a variety of critical reviews of current computing books. The reviews are arranged alphabetically by title, with new content added regularly. Reviews of software, hardware, and accessories are also available via

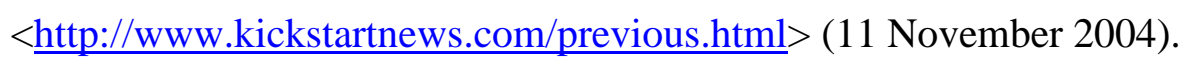

TechBookReport. < <http://www.techbookreport.com/> (11 November 2004). 
TechBookReport furnishes independent, informative book reviews of computing and computer science books. It covers books on software methodologies, software tools, artificial intelligence, machine learning, programming, Java, and XML. Reviews can be located by browsing one of these subject categories, or by keyword search.

\section{DICTIONARIES AND ENCYCLOPEDIAS}

Computing and computer science has an abundance of dictionaries and encyclopedias in print format. There are resources for nearly every level of ability and experience, from home users to researchers and professionals. There are resources that cover the entire discipline and others that address sub-disciplines. It was previously noted in the BOOKS section that CRC Press has four portals that furnish access to online books by subscription or pay-per-title. Many of the titles offered through these portals are encyclopedic handbooks. It was also noted in the same section that the subscriptionbased Xreferplus < $<$ ttp://www.xrefer.com/> (11 November 2004) offers several computing and computer-related dictionaries in its technology section. Other publishers and vendors offer online dictionaries and encyclopedic works. Likewise, there are several free Web-based dictionaries and encyclopedias; they are listed below.

Babel: A Glossary of Computer Oriented Abbreviations and Acronyms.

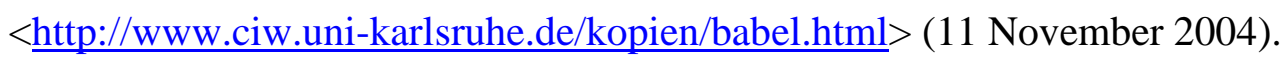

Available on the Internet since 1989, Babel, as the sub-title suggests, covers computerrelated abbreviations and acronyms. It is updated three times a year. 
A Compilation of Software Engineering Terms from Existing Sources.

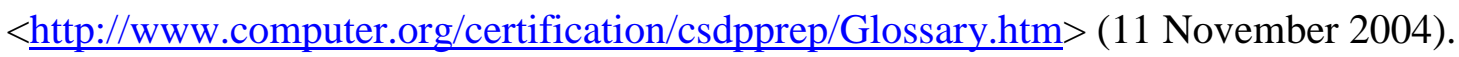
Based in part on the IEEE Standard Glossary of Software Engineering Terminology (IEEE Std 610.12-1990), the purpose of this glossary is to provide definitions for the terms used in the specification of the professional exam. There are numerous crossreferences, and the exact source of the definition is usually furnished.

Dictionary of Algorithms and Data Structures. $<\underline{\text { http://www.nist.gov/dads/> }}$ (11 November 2004).

Hosted by the National Institute of Standards and Technology (NIST), this dictionary provides concise definitions of terms related to algorithms, data structures, archetypical problems, and techniques. Some entries have cross-references to further information and links to implementations.

Free On-line Dictionary of Computing. < $<$ http://foldoc.doc.ic.ac.uk/> (11 November 2004).

The Free On-line Dictionary of Computing is a searchable dictionary of computing. Containing over 13,000 terms, it provides definitions and detailed explanations. Computing Reference $<$ http://www.elook.org/computing/> (11 November 2004) offers another interface and additional features. 
IBM Terminology. <http://www-306.ibm.com/ibm/terminology/> (11 November 2004). The glossaries of several IBM products have been incorporated to form this dictionary. It includes basic computing definitions along terminology from the following IBM brands: CICS, iSeries, Lotus, Tivoli, and WebSphere.

Linktionary. <http://www.linktionary.com/> (11 November 2004).

Based on the McGraw-Hill Encyclopedia of Networking \& Telecommunications by Thomas Sheldon, Linktionary is an online dictionary/encyclopedia of Internet technologies, networking hardware and protocols, and general Web terminology. It provides concise definitions and detailed explanations along with links to additional information.

NetLingo. <http://www.netlingo.com/inframes.cfm> (11 November 2004).

Based on NetLingo: The Internet Dictionary by Vincent James and Erin Jansen, this resource covers terms about the Internet and the World Wide Web, including technology, communication, and business. The definitions are concise and often include crossreferences and links to additional information.

Ritter's Crypto Glossary and Dictionary of Technical Cryptography.

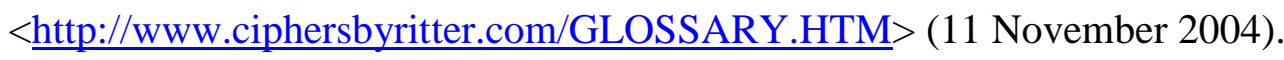
This dictionary explains technical cryptographic terminology. It is arranged alphabetically, with words within entries hyperlinked to other entries for further clarification. It may also be browsed by topic. 
TechEncyclopedia. < $<$ http://www.techweb.com/encyclopedia/> (11 November 2004). Based on an updated and enhanced version of The Computer Desktop Encyclopedia by Alan Freedman, TechEncyclopedia contains more than 20,000 computing and information technology entries. It includes both brief definitions and in-depth explanations. Most entries have illustrations, photos, charts, or diagrams that help elucidate the terminology.

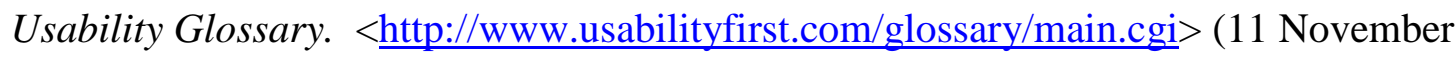
2004).

The Usability Glossary defines over 1,100 usability-related terms.

Webopedia. < http://www.pcwebopaedia.com/> (11 November 2004).

Webopedia is a searchable dictionary of computing and Internet terms that is continually updated with new terminology. Entries include detailed definitions, pronunciation, crossreferences, related terms, and links to additional information.

Wikipedia, the Free Encyclopedia. <http://en.wikipedia.org/> (11 November 2004). The Wikipedia is free, collaborative encyclopedia. It contains articles on all academic subjects including computing and the Internet. Using wiki software, users create its contents, which are subject to editing and revision by other users.

\section{DIRECTORIES AND GUIDES}


This section contains an assortment of Internet directories, guides, and finding aids for computing and computer science. Reference sources for algorithms, biography, career and employment, colleges and universities, journals, meetings and conferences, standards and specifications, and style guides are described. Although there are a few fee-based services, most provide free access.

\begin{abstract}
Algorithms

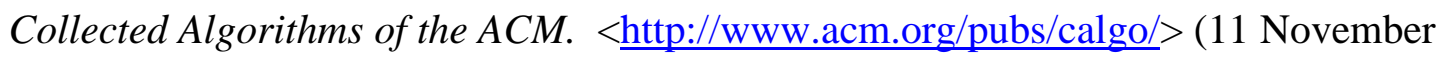
2004).

This collection contains the algorithms published in the ACM Transactions on Mathematical Software and other ACM journals. The algorithms are refereed for originality, accuracy, robustness, completeness, portability, and lasting value. The site begins with algorithm number 493 (issued in 1975), however, earlier algorithms are also available.
\end{abstract}

Cryptography: Algorithms. < November 2004).

This page lists commonly used cryptographic algorithms and methods, and explains their basic concepts. Links are provided to implementations and textbooks.

The Stony Brook Algorithm Repository. <http://www.cs.sunysb.edu/ algorith/> (11 November 2004). 
Based on his book The Algorithm Design Manual, Steven S. Skiena has mounted this site containing a collection of algorithm implementations for over seventy of the most fundamental problems in combinatorial algorithms.

Biography

HomePageSearch. <http://hpsearch.uni-trier.de/> (11 November 2004).

Personal home pages of computer scientists can be located using the search function on this Web page. Using the "author tree" function, names can also be browsed alphabetically. Results include links to home pages and related pages, and a direct links to bibliographies that list the scientist's papers and articles.

\section{Career and Employment}

ACM Career Resource Centre. <http://campus.acm.org/crc/> (11 November 2004).

The Association for Computing Machinery developed this Web site to help students and professionals make informed decisions about employment and careers. It contains a searchable jobs database that includes full time positions, internships, and summer jobs; self-assessment tools; and discussion forums.

Developers.net: Career Index. <http://www.developers.net/careers/> (11 November 2004).

Developers.net provides a comprehensive employment site for information technology and software development professionals. It contains information on thousands of positions in the U.S. This site is free, but users must register. 


\section{Colleges and Universities}

Computer Science Departments Across the Web.

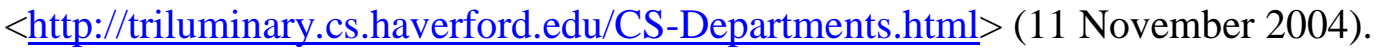

Links to the Web sites of academic computer science departments around the world are listed on this Web page.

Graduate Assistantship Directory (GAD). < http://www.acm.org/gad/> (11 November 2004).

$G A D$ is a publication of the Association for Computing Machinery; it provides information on graduate programs in computing, including degrees offered and specialties, numbers of faculty and students, faculty interest areas, computer equipment available, types and amounts of financial aid available to qualified students, and admissions requirements and application deadlines.

Journals

All That JAS: Journal Abbreviation Sources: Computer Science.

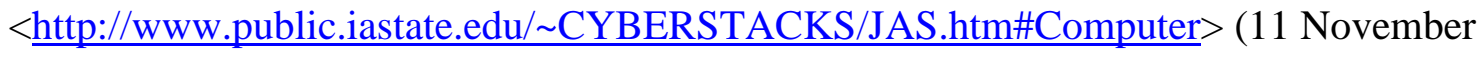
2004).

All that JAS is a listing of Web resources that list or provide access to the full title of journal abbreviations. The computer science section lists two resources.

Computer Science Journals. <http://www.informatik.uni-trier.de/ ley/db/journals/> (11 November 2004). 
Arranged alphabetically by title, this is a directory of selected computer science journals. It provides access to tables-of-contents and the journal's Web page. There are also links to other journal directories.

The Directory of Computing Science Journals.

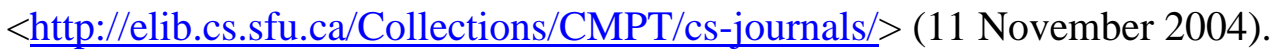

The Directory of Computing Science Journals is a listing and gateway to over 500 computer science and computing journals. Access is provided by an alphabetical list of the titles and a title keyword index. Each journal entry is different but most contain links to its Web page, table-of-contents, abstracts, and full text (for subscribers).

Directory of Open Access Journals: Technology and Engineering: Computer Science.

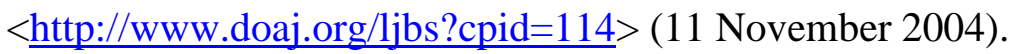

Compiled by Lund University Libraries, the Directory of Open Access Journals lists free, full text scholarly journals. There are currently thirty-nine journals in the computer science section. Each journal entry contains ISSN, subject, publisher, language, keywords, start year, and a link to the journal.

Meetings and Conferences

All Conferences: Computers. $<\underline{\mathrm{http}}: / / \mathrm{www}$.allconferences.com/Computers/> (11

November 2004).

All Conferences is a directory that focuses on up-coming conferences, conventions, trade shows, exhibits, workshops, events, and meetings. It may be browsed by subject 
discipline or sub-discipline, or searched by keyword. Each conference record includes event name, dates, place, subject categories, URL, description, and instructions for presenters

MInd: The Meetings Index. <http://www.interdok.com/mind/> (11 November 2004). Created by InterDok, the publisher of the Directory of Published Proceeding, MInd lists information on future conferences, congresses, meetings, and symposia. It can be searched by a combination of subject keyword, sponsor, location, and year. Each record includes event name and acronym, dates, location, organizer/sponsor, contacts, keywords, and URL.

Standards and Specifications

Internet-Drafts \& RFC Search.

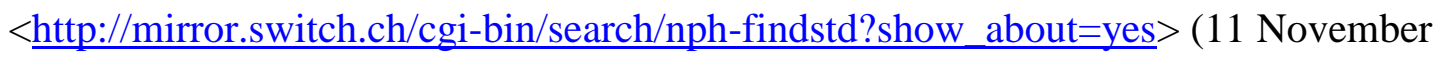
2004).

Two types of documents are available through this Web site: Internet-drafts and RFCs (Requests for Comments). RFCs are official documents of the Internet Architecture Board. They are protocols and policies that never change, are permanently archived, and can be updated with a new RFC. An Internet-draft has no formal status, is valid for only six months, and may become an RFC. Using the keyword search facility, either type of document can be located. Once it is found, the full text is freely available.

Internet Requests for Comments (RFC). 
$<$ http://www.cse.ohio-state.edu/cs/Services/rfc/index.html $>$ (11 November 2004).

Maintained by the Department of Computer Science and Engineering at The Ohio State University, the RFCs in this archive deal specifically with the Internet. Access is provided by an index (numerical range listing), keyword search, and numerical listing. Once an RFC is located, the full text is freely available.

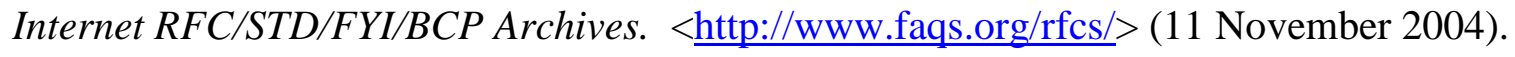
This Web site is an archive for the following Internet documents: RFCs (requests for comments), STD (standards), FYI (for your information), and BCP (best current practices). Searchable by keyword or document number, the archives may also be browsed by several indexes. All documents are freely available.

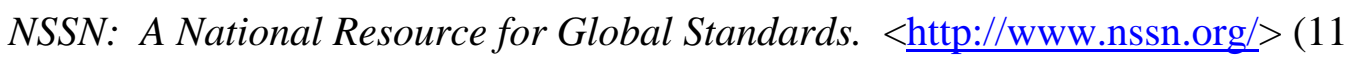
November 2004). NSSN is a partnership of the American National Standards Institute, government agencies, and international and private sector standards organizations. Its Web site can be used to search for and purchase standards from over 600 global sources.

Standards and Standards Organizations.

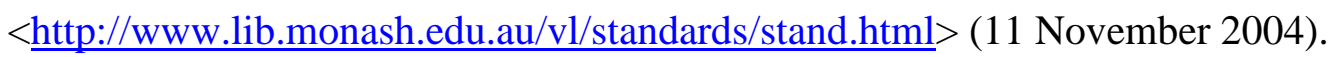

After defining standards, this Web page from Monash University Library lists and describes some the most important international standardization organizations for 
computing, electronics, and information technologies. The descriptions include links to organization's Web site, and directions on locating and accessing their standards.

Techstreet. < http://www.techstreet.com/> (11 November 2004).

Techstreet provides access to standards and codes from over 350 standards organizations. Covering a wide range of industries, including electronics and information technology, this fee-based service delivers documents either by subscription or by individual document. Standards can be searched by keyword, title, ISBN, and document number.

Style Guides

IEEE Computer Society Style Guide. <http://www.computer.org/author/style/> (11 November 2004).

The purpose of this style guide is to clarify editorial styles and standards used in the IEEE Computer Society's publications. It provides a listing of preferred sources for style and usage, as well as guidance on subjects like abbreviations, capitalization, mathematical expressions, non-English words and phrases, program code, punctuation, and references.

Online! Citation Styles. < http://www.bedfordstmartins.com/online/citex.html > (11 November 2004).

Developed by Bedford/St. Martin’s publishers, this guide covers the elements of citing Internet sources for Modern Language Association (MLA) style, American Psychological Association (APA) style, Chicago Manual of Style, and Council of Biological Editors (CBE) style. For each style, the following sources are addressed: WWW site, email 
message, discussion forum posting, listserv message, newsgroup message, real-time communication, and telnet, FTP, and gopher sites. There are also links to other citation styles.

Submitting Articles to ACM Journals.

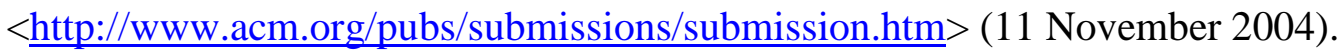

This guide contains instructions for submitting articles to ACM journals in the preferred format of LaTeX and in MS Word format. It includes all of the necessary elements for a typical article along with templates to assist the author. The assignment of indexing terms from the ACM Classification System is also addressed.

\section{CONCLUDING THOUGHTS}

The evolutionary nature of the Internet is apparent in numerous forms and evident by examining the two earlier articles on computer science Internet resources. ${ }^{1,2}$ The editors of the first article have attempted to keep it current by inserting up-to-date URLs (uniform resource locators) for sites that are still active but have different URLs, and by removing URLs for sites that have broken links and are no longer available. Of the original 55 Web sites described, 21 (38\%) have different URLs and 17 (31\%) have disappeared. In nearly eight years, $69 \%$ have either migrated or ceased. An analysis of the second article indicates that 25 of 75 Web sites are not available at the original URL; 33 1/3\% either migrated or ceased about four years after publication. The reasons URLs disappear or migrate fall into two categories: (1) the Web site maintainer loses interest 
and removes the site, or (2) the Web site evolves from a static page to one that is either dynamically generated or uses the latest technologies.

\section{NOTES}

1. Knee, Michael. “Guide to Computer Science Internet Resources.” Issues in Science and Technology Librarianship 15 (Summer 1997), < summer/internet2.html> (11 November 2004).

2. Knee, Michael. "Computer Science: A Guide to Selected Resources on the Internet.” College \& Research Libraries News 62, no. 6 (June 2001): 609-615,

<http://www.ala.org/ala/acrl/acrlpubs/crlnews/backissues2001/june1/computerscience.htm> (11 November 2004). 